\title{
LA REPÚBLICA VIRTUOSA. HONOR, DESINTERÉS Y VOCACIÓN EN LOS DEBATES PARLAMENTARIOS SOBRE LAS DIETAS Y LOS FUEROS EN CHILE (1812-1925)1
}

\author{
THE VIRTUOUS REPUBLIC. HONOR, DISINTERESTEDNESS \\ AND VOCATION IN THE DEBATES OF PARLIAMENTARY \\ ALLOWANCES AND IMMUNITY IN CHILE (1812-1925)
}

\section{AlFREDO JOIGNANT² Y MARÍA COSETTE GODOY ${ }^{3}$}

\section{RESUMEN}

Las dietas y los fueros parlamentarios constituyen dispositivos normales en el funcionamiento del campo político, los que operan hoy en día en el modo de la evidencia. El análisis de su génesis y rutinización en Chile entre 1812 y 1925 a través de los debates parlamentarios a los que dieron lugar, permite mostrar las lógicas sociales y políticas que se encontraron en su origen, en el marco de innumerables batallas entre agentes que eran portadores de definiciones rivales del desinterés y la virtud. El artículo muestra de qué modo estos dos dispositivos incidieron en la diferenciación del campo político y en la autonomización de la esfera parlamentaria, a partir de una sociohistoria de las pasiones políticas, cuyo resultado fue una profunda transformación de sus agentes y del trabajo político.

Palabras clave: Dieta parlamentaria, fuero parlamentario, sociohistoria, campo político, profesionalización de la política.

\section{ABSTRACT}

Parliamentary allowances and immunity are normal devices in the functioning of the political field and operate today in the way of evidence. Analysis of their genesis and routinization in Chile between 1812 and 1925 through the parliamentary debates to which they gave rise reveals their underlying social and political logic in the framework

${ }^{1}$ Este artículo forma parte del proyecto de investigación Fondecyt 1070984, "Profesionalización de la política y saberes de gobierno, siglos XIX y XX". Agradecemos el acompañamiento en la explotación de archivos a Marco Ensignia y Laura Carrera.

${ }^{2}$ Profesor Titular del Instituto de Políticas Públicas Expansivas Universidad Diego Portales (UDP).Santiago, Chile. E-mail: alfredo.joignant@mail.udp.cl

${ }^{3}$ Magíster en Ciencia Política Universidad de Chile. Máster "Politiques publiques et changement social”, Institut d'Etudes Politiques de Grenoble, Grenoble, Francia. E-mail: mcosette@gmail.com 
of numerous battles between agents who were the bearers of rival definitions of disinterestedness and virtue. Through a sociohistory of the political passions involved, this article shows how these two devices affected the differentiation of the political field and the autonomization of the parliamentary sphere that resulted in a profound transformation of its agents and their political work.

Keywords: Parliamentary allowances, parliamentary immunity, sociohistory, political field. professionalization of politics.

Recibido: 02.03.2010. Aprobado: 10.11.2010.

\section{INTRODUCCIÓN}

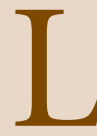

A LITERATURA sobre las dietas y los fueros parlamentarios en Chile es enorme, dos dispositivos que son a menudo referidos como "privilegios"4 . Casi se podría decir que este objeto de estudio ha sido monopolizado por la razón histórica y jurídica, esto es por la restitución de la historia de la función parlamentaria tal como fue experimentada por quienes la ejercieron durante algo más de cien años, y por la construcción de una ortodoxia que la codificaba y ponía en forma. Experiencia y codificación de una misma función, relato y formalización del rol parlamentario, a partir de la descripción y explicación detallada de varias batallas políticas, cuyos resultados terminan siendo oficializados por el código y la ley.

Sin embargo, es poco frecuente dar cuenta de la génesis de estos dos dispositivos, poniendo en evidencia lo que se juega en ellos y sus efectos sobre el incipiente campo político chileno. En tal sentido, un enfoque sociohistórico permite comprender los intereses sociales que se encuentran en juego con ocasión de las controversias referidas a las dietas y a los fueros, al estatus de sus beneficiarios, a los usos de la posición de diputado y senador, a la diferenciación del campo político y la autonomización del espacio parlamentario. En cada una de estas vastas y lentas transformaciones, en donde una empresa de reforma favorable a la adopción de estos dispositivos es seguida por oposiciones y resistencias, lo que predomina son representaciones de lo que legislar y representar quiere decir. Lo que a menudo se olvida es que, tras estas representaciones, son ciertas formas de competencia social y política las

\footnotetext{
${ }^{4}$ Es así como, en un documento de apoyo al proceso legislativo chileno, se señala que "los diputados y senadores, para ejercer sus funciones, gozan de diversos privilegios, entendidos éstos como las ventajas exclusivas o especiales de las que goza por encontrarse en determinado cargo", esto es "los viáticos, las dietas o remuneraciones, y muy particularmente la inviolabilidad y la inmunidad parlamentaria", también conocida como "fuero constitucional" o "fuero parlamentario" (Fuero parlamentario, 2003: 1).
} 
que permiten explicarlas, en el marco de definiciones rivales de la vocación y del desinterés, o si se quiere de la virtud.

El modo de ejercicio de la actividad política ha experimentado un continuo proceso de profesionalización, el que ha coincidido con el propio desarrollo del Estado moderno. Se trata de un proceso complejo, fuertemente vinculado a la universalización del sufragio, gradual en Chile, en contraste con formas más abruptas de extensión del voto que es posible observar en otras latitudes. En tal sentido, la profesionalización de la política es una de las varias manifestaciones del proceso de división del trabajo político, permitiendo a un grupo particular adquirir el monopolio de la representación: el de congresal o parlamentario. Las dietas y los fueros parlamentarios participan de este proceso, lo que justifica interesarse en ellos en un contexto geográfico e histórico particular.

Estos dos dispositivos contribuyen a configurar y demarcar el campo político, en función de historias particulares. Las dietas han acompañado y reforzado, de acuerdo con ritmos muy variables de un país a otro, el proceso de autonomización y diferenciación del campo político, limitando la dependencia de sus agentes respecto de aquellos medios de subsistencia proveídos por la economía o la posición social. En cuanto al fuero, éste actúa como dispositivo que busca evitar que el ejercicio de la política quede a merced de la arbitrariedad del poder ejecutivo tan característica del siglo XIX chileno, así como de los intereses de agentes inscritos en otras esferas de la sociedad.

La génesis de ambos dispositivos en Chile es aquí analizada a través del examen de los debates parlamentarios, en donde se ponía regularmente en cuestión el honor, y hasta la honorabilidad de los involucrados. Para ello, estudiamos el período comprendido desde el inicio de la historia republicana hasta 1925, en el entendido que es allí en donde reside la génesis de ambos dispositivos, en el marco de luchas y controversias que eran a la vez políticas y sociales.

\section{GÉNESIS Y CODIFICACIÓN DE LA DIETA PARLAMENTARIA EN CHILE: DE LA “GRATITUD DE LA PATRIA” A LA OCUPACIÓN REMUNERADA DEL CARGO}

Formalmente, la dieta parlamentaria designa a la retribución económica que reciben los diputados y senadores por el ejercicio de la función legislativa. Como señala Garrigou (1992), en su estudio sobre la dieta en Francia, a menudo se asocia su existencia con la universalización del sufragio mas- 
culino, el cual eliminó los requisitos censitarios para ejercer el derecho a voto. De esta manera, resulta usual vincular su incorporación con el ingreso al campo político de personas sin fortuna que aspiraban a llegar al Congreso sin disponer de los medios económicos suficientes para dedicarse al ejercicio de la actividad legislativa de manera gratuita.

Sin embargo, dicha aseveración no es del todo correcta. Al igual que en el caso francés, la retribución de la función legislativa en Chile comienza a operar a título indemnizatorio con anterioridad a la universalización del sufragio masculino, aunque su consagración definitiva tendrá lugar sólo a partir de la Constitución de 1925.

Uno de los primeros reglamentos del Chile autónomo, el Reglamento para el Gobierno Provisorio de 1814, estableció el principio de gratuidad de la función legislativa. En él se sostenía que el ejercicio de dicha función debía estar motivado por la dedicación y el patriotismo, haciendo gala de una cierta idea de vocación y de desinterés 5 . Este principio se erigió, en los hechos, en una verdadera barrera de entrada al campo político, reforzada, además, por los requisitos censitarios que desde el inicio de la historia constitucional chilena condicionaron el derecho a voto y la posibilidad de optar a cargos de representación política ${ }^{6}$. Una aparente excepción a la gratuidad de la función parlamentaria se presentó cuatro años más tarde, puesto que la Constitución de 1818, dictada en el gobierno de O’Higgins, le asignaba un sueldo anual de dos mil pesos a los cinco vocales que componían el Senado, para entonces un órgano legislativo de carácter provisorio (Monografía de la Cámara de Diputados, 1945 (?): 31). Decimos una aparente excepción, ya que dicho sueldo no tuvo como motivación retribuir la función parlamentaria, sino otorgar un medio de control de dichos senadores por parte del Ejecutivo, transformándolos en empleados públicos avant la lettre. Quizás por ello es que la Constitución de 1822, que preveía por primera vez un sistema bicameral, refiriéndose a la dieta de manera indirecta, estableció la prohibición de los diputados de recibir de parte del Poder Ejecutivo "comisión lucrativa o empleo, que no sea de inmediata escala" (Campos Harriet, 1983: 342).

Serán más bien razones prácticas las que incidirán en la discusión parla-

\footnotetext{
${ }^{5}$ Este Reglamento estipulaba, en el acápite referido al Senado Consultivo, que el servicio de cada uno de sus siete miembros "será sin más sueldo que la gratitud de la Patria" (Muñoz León, 2005: 249).

${ }^{6}$ Ya en la convocatoria a las elecciones al Congreso Nacional de 1811 realizada por la Junta de Gobierno de la época, se recomienda a los electores que "procuren elegir sujetos que tengan bienes suficientes para hacer a su costa este servicio a la patria" (Monografía de la Cámara de Diputados, 1945 (?): 29).
} 
mentaria sobre su necesidad y pertinencia, poniendo en evidencia la precaria condición económica de algunos diputados. En 1823, el Congreso Constituyente, elegido para la discusión y aprobación de la Constitución de ese mismo año, excedió el plazo estipulado para cumplir su labor, obligando a los parlamentarios de provincias a mantenerse en Santiago. Ello implicaba el abandono de las actividades que proveían su mantención y la de sus familias. Sería un diputado por Curicó, Diego Donoso, quien representaría la situación al Congreso mediante una sentida petición, quien incluso renunciaría al cargo por carecer "de lo más necesario para los gastos de manutención en la capital” (Letelier, 1886-1908: 440).

Analizada la solicitud de renuncia por la Comisión de Objetos del Congreso, ésta resolvió lo siguiente:

Soberano Señor:

La Comisión cree poderosísimos los fundamentos, en que apoya su solicitud el señor diputado don Diego Donoso, todo otro embarazo tal vez pueda vencerse, pero no tener subsistencia sólo entra en parangón con no tener salud o vida; pues todos tocamos con todos nuestros sentidos que el que no se alimenta no puede ni vale mas que el que va al sepulcro, así es que la Comisión, cree que, siendo efectiva la numerosa familia y corta fortuna del señor suplicante o se le debe admitir la renuncia, o se le deben dar dietas, previas a las dilijencias prevenidas en el acuerdo del caso (Letelier, 1886-1908: 445).

Finalmente, la Cámara le asignó al mencionado diputado una dieta de dos pesos diarios, pudiéndose estimarse que éste es el primer precedente de una dieta parlamentaria efectivamente concedida.

Llama la atención, sin embargo, la aparente falta de fortuna del mismo diputado. Al parecer, los requisitos censitarios para ser elegido diputado no eran lo suficientemente altos como para evitar este tipo de situaciones. Aunque la convocatoria para las elecciones del Congreso Constituyente de 1823 exigía para ser electo diputado, entre otros requisitos, "contar con bienes suficientes para mantenerse decentemente", no siempre éstos eran tan abundantes como para sufragar los gastos de traslado y estadía en la capital por parte de quienes provenían de las provincias. El historiador Francisco Encina relata que, si bien las funciones legislativas fueron gratuitas para esta ocasión, debido al estado de pobreza, en particular de la provincia de Concepción, se asignó una dieta a los representantes de cada uno de sus distritos que no dispusieran de los recursos suficientes para costear los gastos del viaje y de permanencia en la capital (Encina, 1983: 42).

Estos precedentes sirvieron para que, a partir de 1824, comenzaran a 


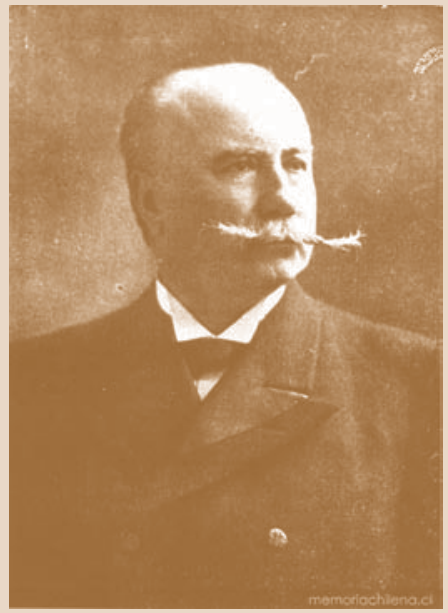

C. Walker Martínez dictarse esporádicamente leyes que autorizaban el pago de dietas y viáticos a aquellos parlamentarios que no disponían de un salario por el desempeño de un empleo remunerado y que residían fuera del lugar de reunión del Congreso. Una ley promulgada el 20 de octubre de 1824 asignó una dieta diaria de cuatro pesos para aquellos parlamentarios que se encontraban en dicha situación. Dos leyes posteriores, de 1829 y 1830, también sancionaron el pago de este estipendio junto con asignaciones de viáticos para costear los pasajes por tierra y mar. Hasta 1851, los presupuestos públicos consideraron una partida relativa al pago de dietas y viáticos a los miembros del Congreso Nacional ${ }^{7}$.

Con todo, si se observa el carácter inestable del pago de dietas durante este período, se constata que ellas consistían más en una indemnización que en un estipendio otorgado por el ejercicio profesional y regular de una función pública. De hecho, ellas estaban destinadas sólo a sufragar los costos de traslado y mantenimiento de los parlamentarios provenientes de provincia. En consecuencia, existía una suerte de reconocimiento tácito del ejercicio por parte de éstos de otra actividad distinta a la parlamentaria, la que constituía la base efectiva de su sustento, aludiendo así a la incipiente frontera entre servicio público y negocio privado.

No es sino hasta finalizando el siglo XIX que la cuestión de las dietas vuelve a plantearse bajo la forma de la remuneración, desplazando paulatinamente la lógica meramente indemnizatoria.

Esta transición desde formas indemnizatorias no estuvo exenta de controversias, y fue puesta por primera vez en el tapete en 1888 por el diputado del Partido Nacional Pedro Montt. Éste promovió un proyecto de reforma a la Constitución de 1833 auspiciado por el Ejecutivo de la época, con el cual se disponía la incompatibilidad entre el cargo de diputado y cualquier función pública remunerada. El mismo diputado, en su discurso de motivos, aprovechó la ocasión para defender la gratuidad de la función legislativa. Para él, tanto ésta como el régimen de incompatibilidades garantizaban la independencia de los legisladores respecto del Ejecutivo. La moción del diputado Montt fue apoyada por los diputados conservadores. Las palabras del diputado Carlos Walker Martínez, adscrito a esta última corriente, reflejan aquello que se encontraba en juego en la moción del diputado Montt:

Deseamos independencia para los Diputados; deseamos que vengan a

\footnotetext{
${ }^{7}$ Navarro Beltrán (1999) extrae estos antecedentes de la discusión senatorial con motivo del proyecto de ley del año 1924 que asignaba el pago de dietas parlamentarias, contraviniendo el texto constitucional de 1833. Véase, Cámara de Senadores (de ahora en adelante CAMSE), 22 de julio de 1924, pp. 1112-1113.
} 
estos puestos a obedecer a sus conciencias, libres de sujestiones e influencias extrañas, i por eso establecemos las incompatibilidades con los empleos rentados ¿Cómo podemos permitir entonces que puedan ser rentados? ¿Cómo podemos aceptar que los aspirantes a ocupar estos puestos no vengan a ellos con el espíritu levantado de servir el país i de sostener su bandera, sino tal vez con el espíritu rastrero de ganarse fácilmente una renta, i para asegurársela para siempre vengan dispuestos a complacer en todo al Gobierno que les puede asegurar su elección? [...]. Estoi persuadido que el habernos mantenido tal como estamos, esto es, no estimando el puesto de representante del pueblo como un medio de lucro i especulación, sino como un cargo de honor, sin tener otro interés al desempeñarlo que el bien del país, ha contribuído a mantener ese prestijio $^{8}$.

La gratuidad de las funciones legislativas fue apoyada, en primera instancia, por la gran mayoría de los diputados, al punto que el diputado Acario Cotapos, del Partido Liberal, otorgó espontáneamente a nombre de todos los liberales su apoyo a la iniciativa del diputado Montt (CAMDI, 23/10/ 1888: 59).

Sin embargo, la reacción de Enrique Mac-Iver, diputado radical, tuvo el mérito de situar la discusión en otro plano, el de la igualdad ante la ley. Este principio de rango superior al de la independencia de la función, ésta última tan típica de la interpretación conservadora, era para él la cuestión que definía si la pretendida gratuidad podía alcanzar rango constitucional:

Me parece que establecer esta idea [la de la gratuidad de la función] en la Constitución sería un procedimiento de todo punto anti-democráctico... Esto significa únicamente, señor Presidente, que queramos que exista algo que es conveniente [la misma gratuidad], pero que dejaría de serlo una vez que se le consagrara en nuestra Carta fundamental, porque estaría en pugna con otro principio mas sagrado, que es el de la igualdad ante la ley, sobre el cual deben descansar todas nuestras instituciones republicanas i democráticas (CAMDI, 23/10/1888: 59-60).

No obstante, la iniciativa del diputado Montt hacía suficientemente sen-

\footnotetext{
${ }^{8}$ Cámara de Diputados (de ahora en adelante CAMDI), 23 de octubre de 1888, pp. 58-59. Es sorprendente constatar la profunda afinidad entre el argumento de la independencia del diputado (socavada por el ejercicio de otras actividades rentadas) y la autonomía del votante al momento de sufragar respecto de los agentes electorales. En ambos casos, la independencia del diputado y del votante se lograría apelando únicamente a la voz de la conciencia, a la vocación y al desinterés inscritos en una verdadera definición honorífica del cargo (de hecho, el diputado Walker Martínez lo califica como un "cargo de honor") o de la posición de elector, sin necesidad de dispositivos específicos por donde se afirme la autonomía virtuosa del parlamentario (como por ejemplo la dieta) o de procedimientos que garantizen el secreto del sufragio del votante (sobres en donde se deposita el voto, y sobre todo la cámara secreta: a este respecto, ver Joignant (2001 y 2002).
}

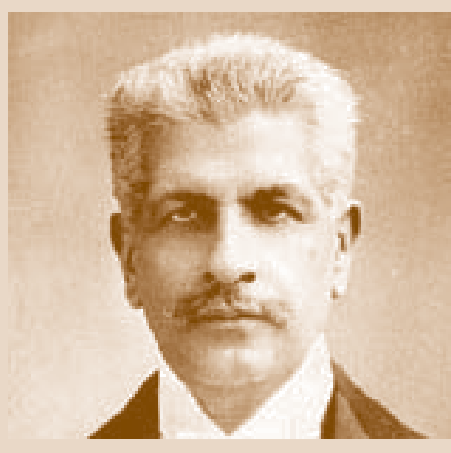

P. Montt 


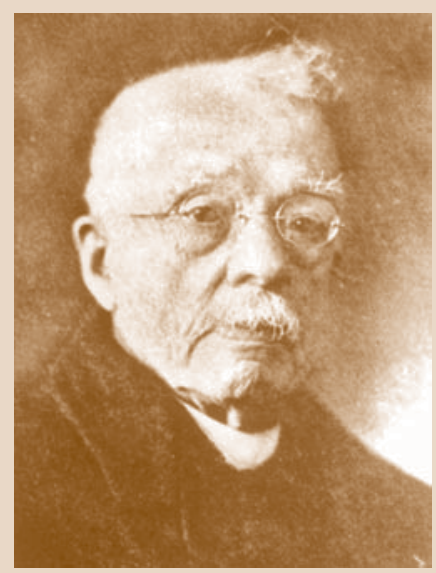

Mac-Iver

tido en la mayoría de sus colegas para desvirtuar la posición de Mac-Iver: iba en ello el prestigio, la fuerza moral, la dignidad y decoro que representaba la consagración gratuita a la Representación Nacional ${ }^{9}$.

Pese a todo, las intervenciones favorables a la remuneración parlamentaria se fueron consolidando entre los diputados de la minoría a medida que se fue prolongando el debate parlamentario, centrándose en la defensa de la igualdad ante la ley. Para ellos, la remuneración de los cargos parlamentarios garantizaría el acceso al campo político a aquellos hombres que no contaban con fortuna, pero sí con la inteligencia necesaria, lo que suscitó airadas réplicas por parte de los diputados conservadores y nacionales. Éstos percibían en el discurso democrático de los radicales y de algunos liberales la peligrosa pretensión de imponer una igualdad social considerada por ellos como contraria a la ley natural:

Por dura que parezca la desigualdad social, es necesaria porque hai un natural sentimiento del hombre que a ella conduce. La misma teoría evolucionista lo reconoce tanto, que ha colocado al frente de su sistema sociológico la consagrada frase de Darwin: Survival the filtest, esto es, sobrevimiento o predominio de los más altos ${ }^{10}$.

Para los conservadores, las desigualdades de origen podían ser superadas de manera individual. El diputado Rafael Errázuriz Urmeneta daba las recetas para ello: la desigualdad económica podía ser derrotada por el trabajo personal; la desigualdad moral por medio del cristianismo; y la desigualdad intelectual a través de la enseñanza. La democracia, en consecuencia, sólo debía otorgar las "facilidades a todos los hombres para subir y colocarse a la altura de los demás..." (CAMDI, 6/11/1888: 158).

La igualdad tampoco podía ser esgrimida respecto de los derechos políticos. La igualdad ante la ley debía garantizar solamente los derechos civiles, ya que los derechos políticos sólo podían ser ejercidos por quienes cumplían con los requerimientos establecidos en la legislación. Si bien en la época en que se sitúa este último debate ya se habían derogado los requisitos censitarios para ejercer el voto masculino ${ }^{11}$, éstos se mantenían para optar a los cargos públicos y de representación:

Los derechos políticos $[\ldots]$, son susceptibles de las más variadas limita-

9 Todas estas alusiones están permanentemente presentes en el debate parlamentario que siguió a la moción del diputado Montt. Véase las sesiones de la Cámara de Diputados de fecha 23, 25, 27 de octubre de 1888 y 6, 8 y 10 de noviembre de 1888 .

${ }^{10}$ Intervención del diputado conservador Rafael Errázuriz Urmeneta (CAMDI, 6/11/1888: 155).

${ }^{11}$ Especialmente a partir de la ley del 12 de noviembre de 1874: al respecto, Joignant (2001 y 2002); Colomer (2004); Valenzuela (1985 y 1998); Posada-Carbó (2000). 
ciones, i no existe país del mundo que no las haya puesto en ejercicio [...]. No todos los chilenos pueden ser ciudadanos activos con derecho a sufrajio, porque los hay innumerables que no saben leer ni escribir. No todos los chilenos pueden ser elejidos miembros del Congreso, ni Ministros de Estado, ni Presidente de la República, porque los hay innumerables que, o no tienen la edad suficiente, o carecen de la renta que se exije, o no han nacido en el territorio de la República (Errázuriz Urmeneta, CAMDI, 6/11/1888: 158).

No puede ser motivo de sorpresa si la remuneración de las actividades parlamentarias fue defendida por algunos diputados de provincia, principalmente de los partidos Liberal y Radical ${ }^{12}$. Del mismo modo que 65 años antes, aunque con una argumentación que incorporaba nuevos elementos de queja, éstos lamentaban la "centralización legislativa" que se producía en Santiago debido a los altos costos que implicaba para ellos el abandono de sus ocupaciones privadas para asistir a las sesiones del Congreso. Más aún cuando meses antes -en agosto de 1888- se había suprimido la figura de los diputados y senadores suplentes, cuya asistencia permitía la obtención de los quórums necesarios para el funcionamiento del Congreso en reemplazo de los parlamentarios propietarios de los cargos.

El mismo Errázuriz Urmeneta rebatió estos cuestionamientos, sugiriendo poner a cargo de los electores o de los partidos políticos el eventual pago de una indemnización a los diputados que debían trasladarse a la capital para cumplir sus funciones. Su discurso trasunta nítidamente una concepción de la representación virtuosa de los intereses, lo que lo habilitaba a entender que el sufragio de sus costos debía provenir "de los electores mismos, o del partido político al que pertenece el candidato," debiendo incluso "resarcirle los perjuicios que el ejercicio [de sus funciones] viniera a ocasionarle” (CAMDI: 6/11/1888: 158). Así, es posible sostener que el punto de vista del diputado Errázuriz no le asigna a la función parlamentaria otro valor que el de la representación desinteresada, deslizando incluso un manto de duda y reproche sobre quienes carecen de la vocación y del decoro gratuito para hacerlo.

La queja de los parlamentarios de provincia, expresada por el diputado liberal Manuel Novoa -quien alegó que sólo podía asistir a las sesiones del Congreso cuando se lo permitían sus “indispensables ocupaciones" (CAMDI, 6/11/1888: 159)-, constituye uno de los varios ejemplos que se dieron al

\footnotetext{
12 Veáse por ejemplo las intervenciones de los diputados liberales Anselmo Blanlot Holley y Manuel Novoa, en CAMDI, 6/11/1888: 137 y 160 respectivamente.
} 
calor del debate respecto del carácter amateur de la actividad. Aún más, este modo aficionado de representar fue esgrimido por los diputados partidarios de la gratuidad como garantía de independencia y decoro. Así lo deja en evidencia el mismo diputado Montt al rechazar la comparación realizada por el diputado Mac-Iver entre el cargo de Presidente de la República, respecto del cual no se cuestionaba su remuneración, y la condición de parlamentario:

Yo no admito [...] la paridad de este ejemplo, pues el puesto de Presidente de la República exige una consagración constante en el que lo desempeña, carácter que no tienen las funciones legislativas, pues son compatibles con los trabajos a que puede dedicarse un individuo para ganarse la vida $[. .$.$] . Lo que queremos [\ldots]$ no es cerrar las puertas del Congreso a cierto número de personas, sino que vengan a él únicamente los que puedan ganarse su vida afuera y que, por consiguiente, tengan asegurada su independencia (CAMDI, 23/10/1888: 61).

Conforme a esta definición, no existirían entonces buenas razones para introducir dispositivos de retribución para los congresales, en quienes se presume una competencia más moral que política, hecha de vocación, desinterés y virtud. Puede entonces entenderse que la dieta, indemnizatoria o de carácter permanente, constituya casi una perversión, no tanto del régimen democrático como del ethos de sus agentes.

Lo anterior se torna aún más cierto a la luz del profundo desprecio de algunos diputados hacia el político profesional, refiriéndolo peyorativamente a la figura del politician o boss norteamericano:

¿Querríamos ver también en Chile nacer y desarrollarse esa funesta plaga de los politicians, de los politiqueros de mala ley, que hacen de la cosa pública su negocio, que especulan con los altos puestos, y que convierten los sagrados intereses que les fueron confiados en vil instrumento de sus pasiones y de su codicia? (Errázuriz Urmeneta, CAMDI, 6/11/1888: 156).

Probablemente todo lo anterior justificaba el apoyo generalizado que en la época suscitaba la idea de independencia de los parlamentarios respecto del Ejecutivo, condición que podía ser afectada por el otorgamiento de una remuneración de origen público. Como se sabe, la Constitución de 1833 había otorgado al Ejecutivo amplias atribuciones ${ }^{13}$. Pero, principalmente, lo

\footnotetext{
${ }^{13}$ Debe precisarse que a partir de los años 1870 tuvieron lugar varias reformas constitucionales dirigidas a limitar las facultades del Ejecutivo y a garantizar las libertades públicas y electoral (Valenzuela, 1985).
} 
que se cuestionaba era su poder de intervención electoral. En efecto, tanto los miembros de las juntas calificadoras como de las revisoras, encargadas del proceso de calificación de los votantes, eran nombrados por los consejos municipales, aunque en la práctica eran las autoridades del gobierno nacional quienes realizaban la selección (Valenzuela, 1997).

Si bien la ley electoral de 1869 prohibió la participación de los representantes locales del gobierno en las juntas calificadoras, y la ley de 1874 dispuso que los miembros de las juntas fueran seleccionados de una lista de los mayores contribuyentes, los opositores al gobierno continuaron denunciando las prácticas de intervención electoral. Aunque es posible advertir diferencias entre los representantes de las diversas fuerzas políticas respecto de la conveniencia de consagrar el principio de gratuidad en la Constitución, el debate parlamentario deja entrever la común percepción que una eventual remuneración de la función parlamentaria pondría en entredicho la independencia del Poder Legislativo, al convertir a los congresales en verdaderos empleados públicos. Sin embargo, la controversia no sólo se refería a esta problemática división de poderes. Esta polémica también aludía al trasfondo moral del ejercicio de la función legislativa, al estar tensionada por una idealizada definición del congresal, cuya consecución natural es el fruto de su independencia social, y no de su sujeción a condiciones económicas de posibilidad, en este caso a la dieta, entendida como dispositivo vulgar y, en cualquier caso, artificial de la virtud.

Puede entonces entenderse que la apasionada defensa de la igualdad ante la ley, lograda a través de la retribución de la función parlamentaria y del servicio público, se plegara durante algún tiempo ante la voluntad mayoritaria de los congresales, por definición hostil a ella. De este modo, prevalecía la gratuidad de la función y por tanto el desinterés de sus agentes, con lo cual se consagraba la eliminación de los presupuestos públicos de la partida referida a dietas y viáticos, vigente desde 1851:

Día llegará en que la libertad electoral sea un hecho, en que los que vengan a este recinto sean elegidos por la libre voluntad de sus electores, $\mathrm{i}$ entonces esos representantes legítimos del pueblo tendrán derecho a una recompensa pecuniaria por sus servicios... Queremos que no se varíe lo existente, porque, dada la actual situación de nuestro país, o no habiendo libertad electoral, conviene que las funciones legislativas sean gratuitas; pero reconociendo el principio de que todo servicio debe ser retribuido, miramos sin temor que pueda llegar una época en que esa retribución tenga lugar. Será justa, conveniente y democrática (Diputado radical Abraham König Velásquez, CAMDI, 25/10/1888). 


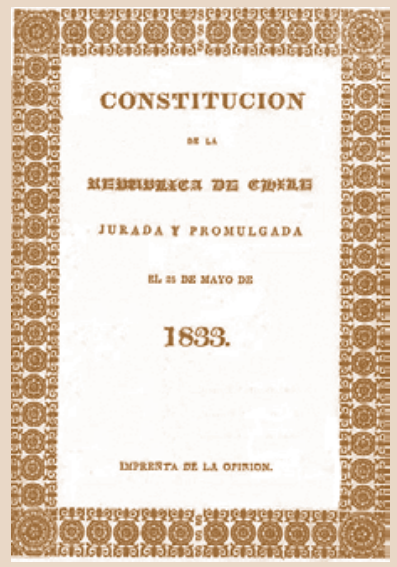

El debate en cuestión se zanjó finalmente a favor de la gratuidad tanto en la Cámara de Diputados como en el Senado, llegando a adquirir rango constitucional a través de una reforma promulgada en 1892.

Las reformas orientadas a democratizar el campo político chileno incidieron poderosamente en el ingreso de nuevas fuerzas en el Congreso, particularmente a través de las leyes electorales dictadas entre 1870 y 1890 . Gracias a estas leyes, se validaba cada vez más la competencia electoral como único medio legítimo para conquistar posiciones de poder político, obligando a los partidos a organizarse y adaptar sus prácticas con el objeto de movilizar el apoyo de un electorado más amplio y heterogéneo. Pero sobre todo, estas transformaciones de la competencia electoral asentaban paulatinamente la creencia de que el trabajo político dejaba de ser el mismo que antes, con lo cual la dieta ganaba en verosimilitud.

La creciente complejidad de la función parlamentaria explica que ya en la primera mitad de la década de 1920 las ideas favorables a la remuneración del trabajo legislativo fueran compartidas por la mayoría de los congresales. Esto expresaba la "corriente igualitaria y democrática que se dejaba sentir en el país" (senador del Partido Nacional Rafael Barahona, CAMSE, 26/08/ 1924: 1604). Es así como en 1920, el diputado del Partido Demócrata Guillermo Bañados propuso reformar el artículo 21 de la Constitución de 1833 que establecía la gratuidad del cargo de senador y diputado. En su alocución, criticaba su carácter antidemocrático, y abogaba por mejorar la calidad del trabajo legislativo (CAMDI, 7/10/1924: 23-24). En su condición de senador, tres años más tarde, Bañados vuelve a insistir en dicha reforma, dejando en evidencia los perjuicios de la gratuidad para la marcha del Congreso. Denunciaba que se "trabajaba poco y de manera deficiente" debido a las recurrentes faltas de quórum tanto en las sesiones como en las comisiones.

Sin embargo, la reforma a la Constitución no era una cuestión simple. Ella exigía su ratificación por dos congresos sucesivos. Con el objeto de evadir dicha restricción, la Cámara de Diputados impulsó en 1924 un proyecto de ley interpretativa de la Constitución destinado a autorizar el pago de asignaciones a los congresales a título de indemnización o gastos de representación, a pesar de la prohibición consignada en el artículo 21. Como es fácil advertir, en la Cámara de Diputados se vuelve a plantear la condición indemnizatoria y no remuneracional de la dieta:

Mientras se despacha el proyecto de reforma constitucional que autoriza la dieta parlamentaria, se declara que la gratuidad del cargo de Senador o Diputado a que se refiere la Constitución, no obsta para concederles 
asignaciones a título de indemnización o de gastos de representación por medio de la ley.

Fíjase en dos mil pesos $(\$ 2,000)$ mensuales la asignación que a este respecto corresponderá a los Senadores y Diputados, a contar desde el $1^{\circ}$ de Junio de 1924... (CAMDI, 13/05/1924: 465-470).

El debate se desarrolló esta vez en el Senado. Prácticamente todas las fuerzas políticas reconocieron la justicia y necesidad de la dieta parlamentaria. Aunque algunos, como el senador del Partido Nacional Rafael Barahona, seguían temiendo los efectos perniciosos de la dieta sobre la independencia de la función legislativa, resaltando el carácter transitorio y, por ende, no profesional de la actividad parlamentaria:

creo que si hay una persona que no puede venir al Congreso porque no le conviene abandonar su trabajo, es mejor que no corte su carrera y que se abstenga de venir aquí, porque si no tiene otra renta para vivir, cuando deje de ser parlamentario tendrá que empezar de nuevo (CAMSE, 26/ 08/1924: 1595).

La oposición al proyecto, encabezada por los senadores de un conglomerado denominado Unión Nacional y que reunía a una facción de liberales y nacionales, se centró en dos tipos de cuestionamientos: en primer lugar, su inconstitucionalidad; y, luego, su inoportunidad, considerando la precaria situación económica que enfrentaba el país. En los hechos, el informe favorable al proyecto emitido por la Comisión de Legislación y Justicia del Senado sólo fue suscrito por cuatro de sus miembros, dos de los cuales dieron exclusivamente su aprobación para efectos de su tramitación, dejando expresa constancia del carácter inconstitucional del mismo. La intervención del senador conservador Romualdo Silva Cortés, integrante de dicha comisión, resume la postura contraria al proyecto:

Yo estoy convencido de que al país, a sus finanzas, a la legislación en general y a la fiscalización conviene la remuneración de los congresales, porque el que recibe un pago presta el servicio mejor; siente mayor responsabilidad; cuida más el patrimonio que guarda o vigila; y está más al alcance de la censura de sus mandantes.

Estas francas y leales declaraciones de mis ideas sobre la materia de fondo, no pueden ni deben servirme, aunque lo sienta, a favor de la ley que se discute, porque la Constitución que he jurado cumplir y respetar me impide alterar el sistema de cargos gratuitos (CAMSE, 26/08/1924: 1605).

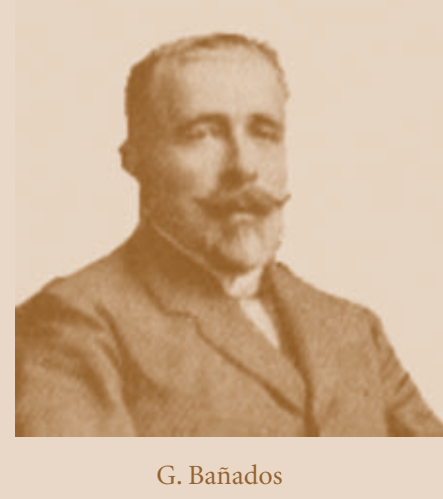




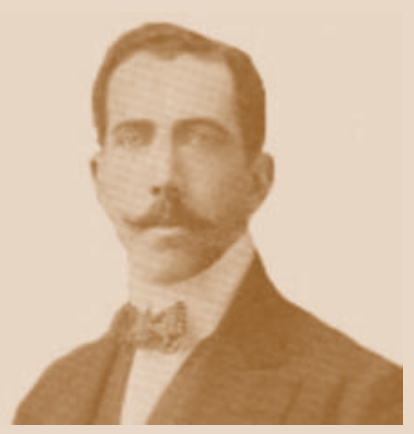

F. Huneeus Gana

Se cuestionaba, además, que el proyecto contravenía el propio reglamento del Senado, el cual prohibía votar asuntos que revistiesen interés directo o personal de los senadores o de sus parientes cercanos:

¿Cómo entonces, señor Presidente, vamos a votar nosotros un proyecto en el cual se trata de asignarnos una renta? [...] ¿Cómo podemos votar, repito, en una materia que nos afecta directa y personalmente? Es evidente que no podemos hacerlo sin contravenir abiertamente las disposiciones contenidas en el citado artículo 101 de nuestro Reglamento (senador conservador Francisco Huneeus Gana, CAMSE, 28/08/1924: 1698).

Por si fuera poco, la dieta parlamentaria de dos mil pesos mensuales se consideraba excesiva e inoportuna, teniendo en cuenta el mal estado de las arcas fiscales. Se alegaba la existencia de sueldos impagos a numerosos empleados públicos; los bajos sueldos de las policías; la cuantía del déficit fiscal; las deudas pendientes con una serie de proveedores y acreedores del Fisco, así como la depreciación de la moneda nacional (CAMSE, 26/08/1924: 1597-1598).

El proyecto fue finalmente aprobado por el Senado el 2 de septiembre de 1924, en contra de la crítica generalizada de la población y, en particular, de los empleados públicos y el ejército. Se cuestionaba la diligencia de los congresales para legislar en provecho propio, en comparación con la lentitud de la tramitación de otras iniciativas más urgentes como el proyecto de subsidios destinado a pagar los sueldos adeudados de los empleados y el proyecto de mejora de las remuneraciones de los militares. Es en este contexto que la oficialidad del ejército interviene con el fin de evitar que fuera promulgada la ley de la dieta, a través del inspector en jefe del ejército general Luis Altamirano, quien le solicita al Presidente de la República Arturo Alessandri interponer su veto a dicha ley y apurar el despacho del proyecto relativo a la situación económica del personal de las Fuerzas Armadas. El desconcierto político era total, habida cuenta que esta intervención castrense ocurría en un marco de generalizada indisciplina partidaria y de desprestigio del Congreso. No parece aventurado sostener que este descontento constituye la primera expresión masiva de crítica social al privilegio del que se benefician los políticos, la que tendrá insospechadas consecuencias.

"Ruido de sables": así fueron conocidas las manifestaciones de molestia de algunos oficiales de más baja graduación motivadas por la iniciativa parlamentaria. El despacho del proyecto de ley de dieta fue el escenario de manifestaciones de militares que pugnaban por mejoras en sus remuneraciones: "doscientos tenientes y capitanes que, con ruidosas manifestaciones, no 
ocultaron su desagrado ante los debates" (Villalobos et alii, 2006: 747). Como es bien sabido, los efectos políticos de este malestar fueron considerables, en la medida en que manifestaban en plenitud la crisis del régimen vigente, estimulando las tendencias presidencialistas que luego se verían confirmadas por la Constitución de 1925. Finalmente, el Congreso Nacional aprobó en las sesiones del 8 y 9 de septiembre de 1924 una serie de iniciativas de corte social, incluyendo la situación de los militares, posponiendo una vez más la decisión referida a la dieta parlamentaria.

No es una casualidad si la dieta parlamentaria, con altos y bajos, fue debatida durante décadas, suscitando adhesiones y rechazos apasionados. Lo que expresa este largo trance fue, en primer lugar, el lento aumento del umbral de tolerancia entre los congresales a la dieta como condición necesaria de ejercicio del trabajo legislativo, lo que implicaba dejar paulatinamente atrás una definición virtuosa y desinteresada de lo que se parecía cada vez más a un oficio parlamentario. De este modo, las pasiones encontradas que eran suscitadas por la dieta no sólo expresaban subjetividades y emociones brutas, independientemente de los argumentos que eran esgrimidos por unos y otros. En efecto, es importante no perder de vista que detrás de estas pasiones lo que afloraban eran definiciones sociales en pugna sobre lo que representar quiere decir, desde el estatus de los representantes hasta su comportamiento político en el hemiciclo, cuya "independencia" -natural y desinteresada para algunos, económicamente imposible de lograr para otros- era unánimemente valorada, aun cuando de esta alegada independencia no se desprendía la misma figura del diputado y del senador. En tal sentido, esta sociohistoria de las pasiones políticas que eran provocadas por los innumerables debates en torno a la dieta, evidencia algo parecido a un proceso de civilización à la Elias, bajo la forma de un dispositivo democratizador del acceso al hemiciclo parlamentario, pero también de permanencia en dicho espacio, contribuyendo a la coexistencia de diputados y senadores de diversos orígenes sociales, e incidiendo por tanto en sus esquemas conductuales, los que debían ajustarse a la compleja morfología social de ambas cáma$\operatorname{ras}^{14}$. Así, la lenta incorporación de la dieta como tema de debate legítimo

\footnotetext{
${ }^{14}$ Como se sabe, la principal manifestación de un proceso de civilización reside en las transformaciones históricas del comportamiento, cuyo refinamiento es el signo de una internalización por los agentes de normas y dinámicas sociales pacificadoras, la que es suscitada, entre otras cosas, por la eficacia de la construcción del Estado y de la división general del trabajo, en este caso político. De este modo, la civilización de la conducta que tiene lugar en un espacio como el hemiciclo permite explicar que con la dieta ingresen a él agentes cada vez más diversos, complejizando progresivamente las relaciones de competencia a través de prácticas sociales ajustadas a su nueva morfología (Elias, 1985 y 1995).
}

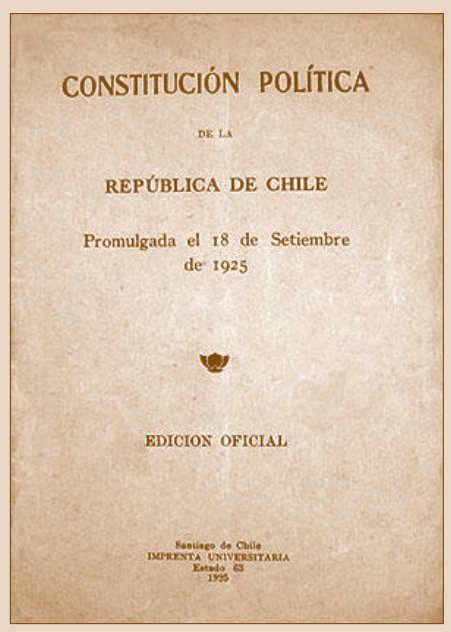


en el Congreso reflejaba los profundos cambios que habían experimentado tanto los electores como los senadores y diputados, cada vez más actores y parte integrante de un campo político que se diferenciaba de otros espacios, ganando en complejidad y en una creciente división del trabajo que tenía lugar en él.

La ironía del episodio de las dietas de 1924 es que concluyó con la renuncia del Presidente Alessandri, al cabo de una primera forma de intervención militar en política, en un contexto en el que, al revés de lo que sucedía en el hemiciclo, el umbral de tolerancia de lo que era visto como un privilegio de los diputados y senadores descendía abruptamente en la sociedad chilena. Pero como suele ocurrir, las coyunturas de crisis pueden ser oportunidades para la implementación de reformas socialmente difíciles. Fue precisamente lo que sucedió con la dieta, puesto que ésta es reconocida por la Constitución de 1925, dejándole a la ley la fijación de su monto.

\section{DE LA DESHONRA PERSONAL A LA INDEPENDENCIA ESTAMENTAL: EL FUERO PARLAMENTARIO}

El fuero parlamentario constituye una prerrogativa procesal destinada a proteger a los congresales de aquellas detenciones y acusaciones penales infundadas efectuadas con la intención de obstaculizar el desempeño de sus funciones. En tal sentido, constituye una excepción al principio de igualdad ante la ley y la justicia, dirigida a asegurar la independencia del Poder Legislativo y la libertad de acción de sus miembros.

En Chile, la institución del fuero parlamentario fue reconocida por primera vez en la Constitución de 1818. En ésta se trataba de una prerrogativa exclusivamente procesal otorgada a los senadores para ser juzgados por una comisión especial, nombrada por el propio Senado, en caso de ser perseguidos judicialmente. Debe recordarse que bajo la Constitución de 1818 rigió en Chile un sistema unicameral, compuesto únicamente por la cámara de senadores. La Constitución de 1822, que consagró, por su parte, el bicameralismo, transfirió dicho privilegio a la Cámara de Diputados.

La inmunidad parlamentaria propiamente tal, esto es la exigencia de autorización previa para someter a juicio a los parlamentarios, fue reconocida por primera vez por la Constitución de 1828. Este texto legal atribuía a la Cámara de procedencia del parlamentario acusado el derecho de declarar si había lugar o no a la formación de causa, salvo en caso de delito flagrante. La Constitución de 1833 no innovó al respecto, aunque fue bajo su vigencia 
que tuvo lugar la mayor parte de las solicitudes de desafuero planteadas durante el siglo XIX. La Constitución de 1925, por su parte, introdujo una importante modificación a dicha institución, al entregar a la Corte de Apelaciones respectiva la competencia para conocer de las peticiones de desafuero.

La historia del fuero en Chile permite dar cuenta de la especialización progresiva de la actividad parlamentaria. Se advierte en las peticiones de desafuero más remotas una clara confusión entre el campo político y las otras esferas sociales, cuestión que limitaba las posibilidades de diferenciación de la función parlamentaria. La solicitud de desafuero realizada por los diputados Daniel Barros Grez y Luis Urzúa, en 1879, en contra del diputado Domingo Víctor Santa María constituye un ejemplo de utilización de dicha prerrogativa para zanjar intereses de tipo personal. El diputado Urzúa acusó a Santa María de hacer mediciones falsas, en calidad de perito, en un juicio seguido por él en contra de una tercera persona, en el cual se discutía el trazado de un acueducto en un predio de su propiedad. Además, otro diputado, Ricardo Letelier, aparecía oficiando como abogado en el juicio representando los intereses particulares de los señores Grez y Urzúa (CAMDI, 1879: 502-531).

Dos cuestiones llaman la atención en esta disputa: por una parte, la confusión entre el rol de diputado y las actividades profesionales de cada uno de los implicados, y por la otra la naturaleza no política del conflicto que moviliza a los mismos. Prueba de lo anterior es la pertenencia común al Partido Liberal de los diputados Urzúa, Santa María y Letelier. El mismo diputado Letelier, en su discurso ante la Cámara, justificaba su comportamiento apelando a su condición de abogado: "Mi deber de abogado me colocaba en la necesidad de continuar en la defensa i de no abandonar a mi patrocinado en las circunstancias más difíciles"(CAMDI, 1879: 548). La expresión de las relaciones de amistad estuvieron regularmente presentes en las intervenciones de los demás diputados en la sala, a propósito de la presentación y discusión del informe de la Comisión de Legislación y Justicia. El diputado liberal Luis Aldunate, en apoyo del acusado, se refiere a dicha acción como "una acusación irritante e injuriosa contra un dignísimo caballero cuya amistad me honro", y justifica su intervención arguyendo la defensa de "un amigo que se ve atacado y agredido por la espalda" (CAMDI, 1879: 502-503).

Lo interesante de este caso es que pone en entredicho una actitud común en la burguesía del siglo XIX, enmarcada por "el concepto del honor y de la caballerosidad", según la cual "un dirigente debía esmerarse por mantener

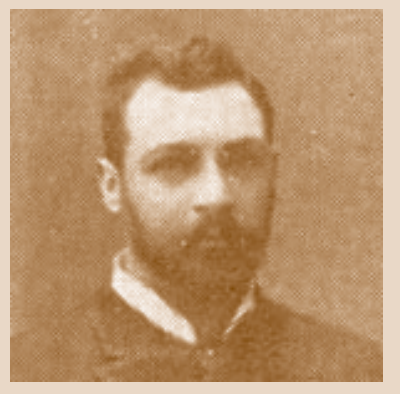

V. D. Santa María 
relaciones de la más perfecta hidalguía con sus adversarios políticos" (Heise González, 1982: 99), cuya infracción fue puesta en evidencia en cada debate referido al fuero. Por añadidura, el informe de la Comisión de Legislación y Justicia se pronunció sobre el real alcance de esta institución. En él, concluía que el caso sometido a su conocimiento "no es de aquellos cuya criminalidad aparezca tan evidentemente justificada" como para autorizar el desafuero del referido diputado. Se reconoció, asimismo, el carácter excepcional de la institución del fuero, recordando que su principal objetivo era garantizar la independencia del Poder Legislativo.

A partir de este caso, las peticiones de desafuero ventiladas en la Cámara de Diputados en los años posteriores estuvieron principalmente vinculadas a la lucha electoral. Sin embargo, si bien los conflictos por desafuero se politizaban paulatinamente, las estrategias y los recursos movilizados por las diversas fuerzas aún revelan la confusión entre campos precariamente diferenciados. En efecto, es en este campo político todavía fuertemente encastrado con otras esferas -en donde se aprecia el predominio de otras relaciones sociales-, que tienen lugar las controversias en la que se combinan politización de las causas y confusiones sociales y personales de las mismas.

En efecto, el fuero parlamentario aparece escasamente utilizado en sus comienzos para lo que podría constituir una demarcación de la propia función. Aún más: este dispositivo se presenta más bien como un dispositivo normativo de referencia para arrastrar al Ejecutivo a dar cuenta de sus acciones en el campo electoral, proporcionando en ese sentido oportunidades para su interpelación. Con el paso del tiempo, sin embargo, y al cabo de varias batallas cada vez menos personales, el fuero tiende a operar como un dispositivo que permite que la política sea enmarcada por un orden jurídico cuya función codificadora de las conductas gana crecientemente en eficacia.

A este respecto, uno de los casos más controvertidos fue el que afectó al diputado conservador suplente por Castro, Silvestre Correa Bravo, a quien se le desconoció su calidad de diputado y fue arrestado por orden del presidente de una de las mesas calificadoras. El diputado afectado había concurrido a fiscalizar el proceso de calificación que se llevaba a cabo en dicha mesa, debido a las irregularidades denunciadas en su composición.

Recordemos que, en aquella época, la inexistencia de registros electorales permanentes era suplida por un sistema de calificaciones a cargo de juntas calificadoras, las que habilitaban a los electores para sufragar en la respectiva elección. Es en este contexto que el diputado Correa había denunciado la falsedad de las residencias de buena parte de quienes aparecían calificados, exigiendo a los vocales de la mesa que se "constatara la residencia 
de todos los que pretendían calificarse" (CAMDI, 11/12/1887: 395). El presidente y el secretario de la mesa, ambos liberales, acusaron al diputado Correa de estar ejerciendo presión sobre los ciudadanos para que no se calificaran, infringiendo según ellos la ley electoral. El diputado Correa fue arrestado por orden del presidente de la mesa y llevado "a un calabozo de cuatro metros en cuadro, en donde a la sazón se encontraban aglomerados treinta individuos descamisados y en tal condición de desaseo que formaban una atmósfera pestilencial" 15 .

Los diputados conservadores presentaron el caso como un atentado a la independencia del Congreso y solicitaron el acuerdo unánime de la cámara baja para pedir las sanciones correspondientes:

¿Podrá la Honorable Cámara permanecer impasible cuando se arrastra a la cárcel pública, como si fuera un malvado, a uno de nuestros colegas, cuyo único delito es ir a vigilar los procedimientos de una mesa calificadora?

Es necesario hoy más que nunca salvar la independencia del Congreso, manteniendo incólume la inviolabilidad de sus miembros consagrada en el artículo 15 de la Constitución y remover cuantos obstáculos se quiera arrojar en su camino para impedir la fiscalización parlamentaria, que es la condición y esencia de vida del régimen representativo (diputado conservador Ventura Blanco, CAMDI, 11/12/1887: 398).

Pero en este caso los llamados a una reacción de carácter corporativo en defensa de la independencia del Congreso terminaron diluyéndose tras las denuncias recíprocas de fraude electoral, lo que dejaba entrever el conflicto entre partidarios del gobierno y la oposición.

La detención del diputado Correa y la publicidad con que fue llevada a cabo fue representada por los congresales opositores como un intento de presión por parte del gobierno sobre los electores. El diputado Puelma Tupper propuso a la Cámara la censura del Gabinete por considerar que éste no había cumplido con su labor de garantizar la libertad electoral y resguardar las inmunidades parlamentarias. Tal petición fue apoyada por los diputados conservadores Carlos Walker Martínez y Juan Barriga, y por el diputado del Partido Nacional Juan Parga. La intervención de Walker Martínez refleja el conflicto existente entre las diversas fuerzas políticas:

15 Relato de los hechos efectuado por el diputado suplente del Partido Nacional, Juan Parga (CAMDI, 12/12/1887: 403).

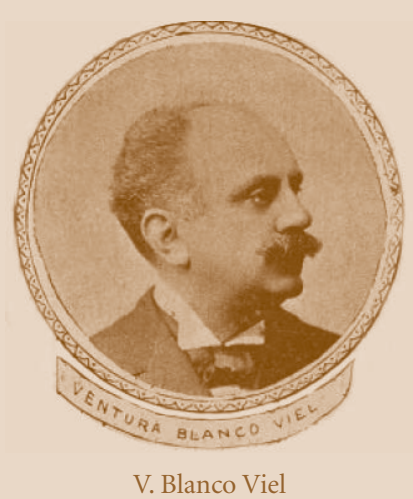


Nosotros hemos dicho que de la situación tirante, irregular, odiosa que atravesamos, es el Ministerio el único responsable dentro del régimen parlamentario. (...). No condenamos al instrumento pagado o servil, condenamos al que usa y emplea el instrumento (CAMDI, 13/12/1887: 422423).

El Ministro de Relaciones Exteriores, Miguel Luis Amunátegui, excusó la responsabilidad política del gobierno argumentando la independencia de las juntas y comisiones electorales reconocida por la ley de 1884. Esta última, promulgada con el objeto de terminar con la intervención del Poder Ejecutivo, confirió a las juntas el derecho a demandar el auxilio de la fuerza pública, obligando a las autoridades administrativas a proporcionárselo de inmediato. Además, reconoció a sus integrantes, durante el ejercicio de sus funciones, similares prerrogativas de inviolabilidad que aquellas que benefician a los diputados y senadores, lo cual denotaba una generalizada autonomía de todos los actores de una elección.

Sin embargo, a pesar de las reformas introducidas, la participación electoral siguió supeditada a prácticas de control por parte de los partidos. El trámite de la calificación introducía una importante distorsión en la dimensión del cuerpo electoral, limitando los efectos de la ley de 1874 que había derogado los requisitos censitarios para votar. En consecuencia, no todos quienes se encontraban habilitados por ley para acreditar su calidad de elector, a través de la calificación, lograban hacerlo. Eran más bien los vocales de los dos principales partidos en pugna quienes autorizaban la calificación de tal o cual sujeto, de acuerdo con sus cálculos políticos:

Con esta mesa se hizo un arreglo entre los comisionados del partido liberal y los del partido conservador. Este arreglo consiste en lo siguiente: que no pudiendo esa mesa funcionar por los tumultos, se convino en que entraran tres a calificarse como mayoría por el partido liberal y dos como minoría por el partido conservador. Se estableció también la condición, puesta por los liberales, de que toda persona decente que se presentara, se calificaría en el acto, aunque la mesa estuviera rodeada por los cinco ciudadanos de los dos partidos" (diputado liberal Acario Cotapos, CAMDI, 15/12/1888: 458).

Del mismo modo que con la dieta parlamentaria, el debate suscitado por el arresto del diputado Correa Bravo dio lugar a luchas entre definiciones referidas a la naturaleza y los límites del mandato parlamentario, en donde afloraban juicios sociales sobre la decencia, la honorabilidad y la virtud, verdadero trasfondo de la controversia que enfrentaba a partidarios del gobier- 
no y de la oposición. Es así como, según el diputado Roldán del Partido Liberal, su colega Correa habría actuado frente a la mesa calificadora en calidad de "agente" y "representante" del Partido Conservador, y no en condición de diputado:

... conviene llamar la atención a un hecho al cual no se le ha dado toda su importancia, y es el de que nuestro colega no se encontraba ejerciendo funciones parlamentarias ni era reconocido en su carácter de Diputado [...]. El honorable señor Correa Bravo no era mas que un agente político, y a este título no podía exigir mayores respetos que los que, como a tal, le eran debidos (CAMDI, 14/12/1887: 447).

Por otra parte, la sujeción a la legislación aparece constantemente esgrimida como límite de la actividad parlamentaria. Los diputados liberales cuestionaron el comportamiento del diputado Correa ante la mesa calificadora, considerando la posibilidad de que haya infringido la ley electoral:

El representante del partido y Diputado que ejecutaba un atropello penado por la ley, estaban igualmente sujetos a su jurisdicción [...]. No pienso que los Diputados estemos por encima de las leyes, sino que, al revés, creo que nuestro mismo carácter de tal nos coloca en la condición de ser especialmente respetuosos y deferentes a ellas. Las inmunidades parlamentarias no son la impunidad parlamentaria. Las disposiciones constitucionales que a nosotros se refieren no tienden a convertirnos en una casta privilegiada, sino a garantizar nuestra independencia"(CAMDI, 14/12/1887: 447).

Difícilmente se podía ser más claro respecto de lo que se encontraba en juego, ya que todos los términos empleados por el diputado Roldán, estar o no por encima de las leyes, los riesgos de transformarse en una casta privilegiada, la independencia de la función legislativa, expresan precisamente la problemática diferenciación del campo político y de su esfera parlamentaria, así como la difícil autonomía de sus agentes. El diputado y ministro de Industrias y Obras Públicas, Pedro Montt, incluso fue más allá. La persona del diputado era para él un funcionario público y en dicha condición debía "abstenerse de intervenir o ejercer presión sobre las mesas" (CAMDI, 21/ 12/1887: 546). Llama la atención que tal homologación no haya suscitado una mayor reacción de los demás congresales, a diferencia de lo que pudimos observar en el caso de la dieta parlamentaria. Recordemos que casi un año después, el mismo diputado Montt promovió la gratuidad de la función parlamentaria frente al peligro de transformar, a través de la remuneración, a los diputados precisamente en funcionarios públicos. Esta aparen- 
te contradicción se explica por la coexistencia de dos definiciones de la función parlamentaria y de sus agentes: por una parte, una definición virtuosa que se desprende de los debates en torno a la dieta, en la que predomina la lógica de la vocación y del desinterés; por otra parte, una definición funcional de la actividad parlamentaria, en donde lo que importa es la autonomía e independencia de su ejercicio, tal como se puede inferir de las innumerables controversias referidas al fuero parlamentario. Sin embargo, y más profundamente, lo que refleja esta tensión entre definiciones rivales es la persistencia del rechazo a hacer del oficio parlamentario una profesión separada de otras actividades, dotada de estatus, privilegios e intereses inscritos en los usos de la posición de diputado y senador.

Finalmente la moción de censura al Gabinete fue rechazada por una amplia mayoría sin que fuese posible lograr algún tipo de acuerdo respecto de la vulneración del fuero parlamentario del diputado Correa Bravo. Sin embargo, el interés de este caso reside en que muestra, a la manera de una radiografía de las pasiones políticas, cómo un dispositivo como el fuero objetiva la posición parlamentaria (en este caso, de modo problemático), a la vez que demarca y diferencia el espacio parlamentario respecto de otras esferas (gubernamental, civil, de la vida privada, personal y profesional). En tal sentido, las polémicas en torno al fuero participan del lento trabajo colectivo de desencastramiento y separación del campo político. Si es posible hablar de trabajo colectivo, ello se debe a que todas las controversias en torno al fuero pasaban generalmente por alto los alineamientos y pertenencias partidarias de los diputados y senadores, con lo cual se afirma que lo que se encontraba en juego era el destino de todo el espacio parlamentario, de sus agentes, del estatus asociado a ellos, de la manera de ingresar y permanecer en dicho espacio, y por tanto del modo de habitarlo.

La solicitud de desafuero en contra del senador suplente del Partido Liberal Democrático, José Francisco Gana, representa un caso aún más revelador de las confusiones de roles que fundan dicha petición. Al senador Gana se le acusó de transgredir la ley de elecciones por "negarse a prestar en el carácter de comandante general de armas de la provincia de Santiago, el auxilio de la fuerza pública que se pidió por una de las juntas receptoras" (CAMSE, 29/07/1888: 171). El aludido fundamentó su negación dando a conocer la orden que había recibido del intendente de provincia, quien le había solicitado poner a su disposición las fuerzas de ejército de su guarnición con el objeto de evitar situaciones de conflicto entre estas últimas y las fuerzas de policía que se encontraban bajo dependencia de la Intendencia. El informe de la Comisión de Legislación y Justicia rechazó la solicitud, aun- 
que sus integrantes fundamentaron dicha negativa esgrimiendo diversos argumentos, llegando incluso a pronunciarse sobre la cuestión de fondo, con lo cual se invadía la competencia del órgano judicial. Prueba de ello es la argumentada justificación de su decisión por parte de uno de sus integrantes, destinada no sólo a rechazar la petición de desafuero, sino también a eximir de responsabilidad al senador acusado:

Si bien el señor comandante general de armas incurrió en el delito electoral de que se le acusa, su responsabilidad está cubierta por una orden de su jefe jerárquico, el señor Ministro de Guerra, que le autorizó para obrar de esa manera (CAMSE, 29/07/1888: 194).

Es esta última circunstancia la que motiva al senador liberal Adolfo Ibáñez a explicar en la sala su opinión, la única por lo demás que era favorable al desafuero. Según el senador Ibáñez, los antecedentes expuestos otorgaban suficiente testimonio de la existencia de un delito electoral, no correspondiéndole a la comisión ni a la Cámara pronunciarse sobre el fondo de la cuestión. Para reforzar su posición, razonaba sobre los fundamentos del fuero parlamentario, enfatizando que dicha prerrogativa es otorgada a la Cámara a la cual pertenece el parlamentario, con el objeto de salvaguardar la independencia e inmunidad de sus miembros. A su juicio, la acusación dirigida en contra del senador Gana no tenía "en manera alguna el propósito de impedir a éste el cumplimiento de sus deberes como miembro de esta Cámara. Lejos de ello, lo único a que aspiran es a que se coloque al señor Senador inculpado en condiciones de un ciudadano cualquiera para comparecer ante los tribunales de justicia" (CAMSE, 30/07/1888: 201).

Las reformas que tuvieron por objeto limitar la influencia del Ejecutivo y desterrar las prácticas fraudulentas de los procesos electorales se hicieron sentir durante los años siguientes. Aunque las acusaciones de fraude siguieron estando presentes, éstas dejaron de protagonizar las peticiones de desafuero. En los años que anteceden la promulgación de la Constitución de 1925, éstas versarán sobre la imputación de delitos comunes, tales como ebriedad, estafa, defraudación de dineros públicos, etc., vale decir comportamientos sociales que se apartaban de la definición desinteresada y virtuosa del congresal. No obstante, la invocación de motivaciones de revancha política seguirá siendo el principal argumento de defensa por parte de quienes eran destinatarios de acusaciones de conductas ilícitas o impropias, lo que constituía un recurso de politización de las controversias, verdadero eufemismo destinado a transfigurar la falta de decoro y los riesgos de deshonra. La mayoría de dichas solicitudes fue rechazada por las Cámaras respectivas, lo que 
motivó el surgimiento de cuestionamientos a la imparcialidad de las mismas. No podía ser de otro modo, puesto que la historia del fuero incorporaba paulatinamente su condición de dispositivo de demarcación estatutaria de la función parlamentaria, y de autonomización de dicho espacio y de sus agentes, cada vez más regidos por lógicas de funcionamiento que les eran propias.

Lo anterior se aprecia nítidamente en la crítica formulada por un licenciado en derecho, Belisario Troncoso (1900: 15), a principios del siglo XX, cuyo interés no reside tanto en el valor intrínseco de su razonamiento jurídico como en las consecuencias que el fuero tuvo sobre la autonomización del espacio parlamentario:

... la única misión de las Cámaras es ver si la acusación tiene visos de seriedad y reposa sobre cargos reales [...]. Nuestros congresales no lo han pensado nunca así. Si han dado alguna vez lugar al desafuero lo han hecho inspirado en altos ideales de politiquería; pero lo más frecuente ha sido que, estrechando filas en nombre de un noble espíritu de cuerpo o de casta hayan negado lugar al desafuero pedido, a pesar de resultar el delito completamente comprobado y la persona del delincuente individualizada.

El mismo Troncoso criticaba, además, la reforma al Código de Procedimiento Penal vigente en la época, la que determinaba que el rechazo de la Cámara a la solicitud de desafuero producía efectos vinculantes sobre el tribunal que seguía el proceso en contra del congresal, el que debía decretar el sobreseimiento definitivo de la causa y su posterior archivo.

La fundamentación de esta crítica tuvo recepción en los redactores de la nueva Constitución de 1925, quienes finalmente retiraron a las cámaras el derecho de resolver sobre las peticiones de desafuero. En adelante, sería la Corte de Apelaciones en primera instancia y la Corte Suprema en segunda, las que deberían declarar si había lugar o no a la formación de causa en contra de un congresal. Si bien el acuerdo que transfirió la competencia hacia la sede judicial fue unánimemente adoptado por los miembros de la subcomisión encargada de estudiar el tema, en el seno mismo de la Comisión Constituyente el senador comunista Manuel Hidalgo puso en cuestión la independencia de los tribunales de justicia para actuar con la debida imparcialidad. Además de considerar la antigua atribución de las cámaras como un derecho adquirido, vislumbraba un cierto peligro de intervención por parte del Ejecutivo. Su temor no era del todo injustificado, teniendo en consideración que la nueva Constitución otorgaba al Ejecutivo la atribución de 
nombrar a los ministros y fiscales de la Corte Suprema de una lista de cinco nombres propuestos por el mismo tribunal. Sin embargo, el giro presidencialista de la nueva Constitución terminó distorsionando este dispositivo de demarcación del campo político, para situarlo en el contexto del derecho y, desde allí, en un ámbito de acción más cómodo para el Ejecutivo, dadas las condiciones políticas de la época. Su deriva en el período que sigue a la promulgación de la Constitución de 1925 es, sin embargo, otra historia.

\section{CONCLUSIÓN}

El estudio sociohistórico de la dieta y el fuero parlamentario en Chile permite dar cuenta del proceso de diferenciación del campo político, de autonomización del espacio parlamentario y de objetivación de las posiciones electivas al interior de este último.

En las primeras décadas de vida independiente, la representación parlamentaria era interpretada como la mera expresión de intereses de ciertos grupos que reclamaban un derecho de acceso al campo político, a través de fuerzas organizadas que terminarían transformándose en partidos, primero parlamentarios, y luego políticos, a medida que se extendía el sufragio en Chile. Durante varias décadas, el pago de las dietas tuvo por objetivo sufragar únicamente los costos de traslado y mantenimiento de los congresales de provincia. De esta manera, la dieta indemnizatoria calzaba perfectamente con las significaciones que los propios congresales brindaban a la función legislativa, concebida como una actividad secundaria y temporal que no debía ser ejercida como una profesión.

Las reformas democratizadoras de la vida política chilena incidirán lentamente en la transformación de los usos y significados de la dieta parlamentaria. La derogación de los requisitos censitarios para el ejercicio del sufragio masculino, en 1874, produjo un aumento importante en el número de votantes, lo cual favoreció la aparición de nuevos conflictos y la emergencia de nuevas fuerzas políticas. Por su parte, las reformas dictadas entre los años 1870 y 1890, dirigidas a garantizar la libertad electoral, validarán la competencia por los votos como el único medio efectivo para alcanzar posiciones de poder político, cuestión que se encuentra en el origen de lo que cabe entender por partidos propiamente tales en Chile.

De esta manera, la gratuidad de la función legislativa dejará de ser funcional y, sobre todo, socialmente pertinente, dadas las profundas transformaciones que afectan al electorado y que inciden en las formas de la compe- 
tencia electoral. Aunque la instauración de la dieta remuneracional se enfrentará a varias trabas normativas y económicas, lo que subyace a estas resistencias es la peyorativa definición de la actividad parlamentaria como profesión, duraderamente asociada a formas corruptas y clientelares, y sobre todo apartadas del ideal virtuoso y desinteresado del legislador.

Los debates en torno al fuero parlamentario participan del mismo proceso. Las peticiones de desafuero más remotas evidencian una clara confusión entre el campo político y las otras esferas sociales. Posteriormente, dichas solicitudes estuvieron fuertemente vinculadas a la lucha electoral y a las prácticas que dominaron el campo político durante la segunda mitad del siglo XIX. De esta manera, el fuero era utilizado como dispositivo orientado a interpelar al Ejecutivo por sus acciones en la lucha electoral. El uso del fuero parlamentario condujo a una serie de críticas, cada vez más políticas, delatando de esta forma la creciente autonomización del Congreso y de sus agentes. Algunas de estas críticas fueron recogidas por los redactores de la nueva Constitución de 1925 quienes, finalmente, despojaron a las cámaras del derecho de resolver sobre las peticiones de desafuero, entregándolo a las cortes.

Lo que se juega, entonces, en los debates sobre las dietas y los fueros, es la diferenciación del campo político y del espacio parlamentario, un proceso complejo y a menudo contradictorio, marcado por avances y retrocesos al cabo de innumerables batallas indisociablemente políticas y sociales, en donde las victorias y derrotas no son nunca completamente definitivas. Se trata de luchas entre los ocupantes de las posiciones parlamentarias, a menudo enfrentados además al Poder Ejecutivo bajo la común reivindicación de independencia, aunque promoviendo definiciones rivales de la virtud. Una independencia no sólo referida a los miembros del gobierno de turno, sino también respecto de otros campos, agentes e intereses. En tal sentido, la sociohistoria de estos dos dispositivos hace suya la historia social de la esfera parlamentaria y de sus agentes, quienes ejercen cada vez más sus funciones de congresales como indígenas del campo, esto es como agentes naturales y legítimos del trabajo legislativo, largamente virtuosos en sus modos de habitar y apropiarse de dicho espacio. Precisamente porque las ideas rivales de virtud de las que eran portadores no se distribuyen homogéneamente en la sociedad chilena del primer siglo de vida independiente, es que se les puede calificar como agentes especiales, en quienes la vocación tantas veces solicitada para autodefinirse como miembros de un estamento de hombres notables, redunda en una duradera exclusión de aquellos otros que carecían de posición (obreros, empleados y ciertamente mujeres).

A medida que avanzaba el siglo XX, es la propia definición de este esta- 
mento de hombres y mujeres notables que es objeto de transformación, cuya fisonomía social se vuelve cada vez más incomparable con las representaciones de la vocación y la virtud que predominaban previamente. En esta otra sociohistoria del campo político, las dietas y los fueros siguen desempeñando una función diferenciadora, aunque cada vez más desde los usos políticos que ambos dispositivos admiten, concebidos como recursos para eliminar del juego a los adversarios. Al transformarse en recursos legítimos de la competencia política al cabo de nuevas formas de lucha cuyo estudio trasciende los límites de este trabajo, lo que se desprende es una radical autonomización de este espacio de contienda, la que es a menudo denunciada por los propios profesionales de la representación política. Dos botones de muestra servirán para demostrarlo.

El primero se refiere a una sentencia del Tribunal Constitucional del mes de agosto del 2006, que declaró inaplicable el inciso $3^{\circ}$ del artículo 416 del Código Procesal Penal en contra del senador Guido Girardi (PPD) referido al procedimiento de desafuero en el caso de delitos de injuria y calumnia de acción privada. Si bien el diputado Marcelo Forni (UDI) lamentaba que el fuero se haya convertido, "al menos para el caso de los delitos de injuria y calumnia, en una protección absoluta, en una virtual garantía de inmunidad" (Forni, 2007), parece razonable interesarse en los usos estratégicos del fuero, habida cuenta de las relaciones de competencia de los partidos a los que pertenecen ambos congresales, no sin antes tomar nota de la profunda autonomía que este dispositivo ha adquirido.

El segundo ejemplo se refiere a la propuesta de reforma presentada por cuatro senadores socialistas en el mes de abril de 2007, a propósito de la designación de "parlamentarios suplentes en los casos de desafuero o cuando el legislador lleva más de 130 días sin poder ejercer su cargo"16, en virtud de la amenazada regularidad de la actividad legislativa y de la necesidad de garantizar a los electores su representación en el Congreso. También aquí se aprecia el uso del dispositivo como recurso de competencia, en este caso de modo defensivo para enfrentar los embates provenientes de los rivales al interior del hemiciclo.

Si a lo anterior se suman las inagotables controversias suscitadas por los reajustes del monto de las dietas y de algunos privilegios de los que se benefician los congresales, desde las partidas presupuestarias concedidas para la gasolina hasta la discrecionalidad en el uso de los fondos para contratar

16 "Presentan reforma constitucional para designar parlamentarios suplentes en casos de desafuero",en: www.senado.cl, Departamento de Prensa, Boletín No 4894-07. 
estudios y funciones de asesoría, lo que allí se revela son siempre pasiones políticas, en donde unos abogan por la austeridad y otros por la dignidad de la función.

¿Cómo se pudo llegar a estas posibilidades de usos estratégicos de las dietas y los fueros? He allí otra historia, moderna y mucho más familiar para el ciudadano del siglo XXI, cuyas manifestaciones en el presente deno$\tan$ transformaciones estructurales que siguen afectando al campo político.

\section{REFERENCIAS}

Campos Harriet, Fernando. 1983. Historia constitucional de Chile. Las instituciones políticas y sociales. Santiago: Editorial Jurídica.

Colomer, Josep. M. 2004. “Taming the Tiger: Voting Rights ans Political Instability in Latin America", Latin American Politics and Society, vol. 46, 2: 29-58.

Elias, Norbert. 1985. La société de cour. París: Flammarion.

Elias, Norbert. 1995. El proceso de civilización. Investigaciones sociogenéticas y psicogenéticas. Buenos Aires: Fondo de Cultura Económica.

Encina, Francisco A. 1983 (1949). Historia de Chile: texto original completo. Santiago: Ercilla, vol. 17.

Forni, Marcelo. 2007. “Desafuero por injurias y calumnias”, El Mostrador, 5 de abril.

Garrigou, Alain. 1992. "Vivre de la politique. Les “quinze mille", le mandat et le métier", Politix, 20: 7-34.

Heise González, Julio. 1982. El periodo parlamentario, 1861-1925, Tomo II, Democracia y gobierno representativo en el periodo parlamentario (Historia del poder electoral). Santiago: Editorial Universitaria.

Joignant, Alfredo. 2001. "El lugar del voto. La ley electoral de 1874 y la invención del ciudadano-elector en Chile", Estudios Públicos, 81: 245-275.

Joignant, Alfredo. 2002. "Un sanctuaire électoral. Le bureau de vote et l'invention du citoyen-électeur au Chili à la fin du XIXème siècle au Chili", Genèses. Sciences sociales et histoire, 49, diciembre: 29-47.

Letelier, Valentín (comp.). 1886-1908. Sesiones de los cuerpos lejislativos de la República de Chile 1811-1845. Santiago: Imprenta Cervantes, vol. 8.

Monografía de la Cámara de Diputados, Chile. 1945 (?) Santiago.

Muñoz León, Fernando. 2005. "Notas sobre la Historia Constitucional de Chile: génesis y evolución entre 1814 y 1970”. México, DF: Anuario de Derecho Constitucional Latinoamericano.

Navarro Beltrán, Enrique. 1999. “La dieta parlamentaria en Chile: antecedentes histórico-institucionales y su consagración en la Constitución de 1980", Ius Publicum, 2: 103-118.

Posada-Carbó, Eduardo. 2000."Electoral Juggling: A Comparative History of 
the Corruption of Suffrage in Latin America, 1830-1930", Journal of Latin American Studies, vol. 32, 3: 611-644.

Troncoso, Belisario. 1900. "Inmunidades parlamentarias". Memoria de Prueba, Licenciatura en Leyes y Ciencias Políticas, Universidad de Chile, Santiago: Lib. Impr. y Enc. "Artes i Letras".

Valenzuela, J. Samuel. 1985. Democratización vía reforma: la expansión del sufragio en Chile. Buenos Aires: Ediciones del IDES.

Valenzuela, J. Samuel. 1997. "Hacia la formación de instituciones democráticas: prácticas electorales en Chile durante el siglo XIX”, Estudios Públicos, 66: 215-257.

Valenzuela, J. Samuel. 1998. "La ley electoral de 1890 y la democratización del régimen político chileno”, Estudios Públicos, 71: 265-296.

Villalobos, Sergio; Silva, Osvaldo; Silva, Fernando y Estellé, Patricio. 2006 [1974]. Historia de Chile. Santiago: Editorial Universitaria. 